\title{
Distribution Pattern of Anchorage Stress and Water Sensitivity Analysis of Red Clay
}

\author{
Lifeng Li $\mathbb{D}^{1,2,3}$ Weili Gong, ${ }^{2,3}$ Huilin Deng, ${ }^{1,2}$ Xiaohu Zhang, ${ }^{1}$ and Gan $\mathrm{Li}^{2,3}$ \\ ${ }^{1}$ School of Architecture and Civil Engineering, Guizhou University of Engineering Science, Guizhou, Bijie 551700, China \\ ${ }^{2}$ School of Mechanics and Civil Engineering, China University of Mining \& Technology, Beijing 100083, China \\ ${ }^{3}$ State Key Laboratory for Geomechanics \& Deep Underground Engineering, China University of Mining \& Technology, \\ Beijing 100083, China \\ Correspondence should be addressed to Lifeng Li; lilifengbj@126.com
}

Received 16 October 2019; Revised 11 December 2019; Accepted 17 December 2019; Published 19 February 2020

Academic Editor: Vadim V. Silberschmidt

Copyright (C) 2020 Lifeng Li et al. This is an open access article distributed under the Creative Commons Attribution License, which permits unrestricted use, distribution, and reproduction in any medium, provided the original work is properly cited.

\begin{abstract}
Red clay is a special soil layer with complex engineering properties distributed in tropical and subtropical regions. An anchor cable support is a common form of red clay slope support. The effectiveness of the anchor cable support is mainly determined by the anchoring force provided by the red clay stratum. Increase of the water content will lead to the rapid deterioration of the mechanical properties of red clay, which will lead to the reduction of the anchoring force of the slope anchor cable and lead to the failure of the support. Based on the classical Phillips and uniform anchorage shear stress distribution theory, this paper puts forward a uniform-exponential distribution pattern of anchorage shear stress according to the specific characteristics of red clay by using the characteristics of the peak shear strength and residual shear strength of the rock and soil mass. With increasing anchorage force, the dynamic evolution (single exponential distribution $\longrightarrow$ double single exponential distribution $\longrightarrow$ uniform index exponential complex distribution $\longrightarrow$ uniform distribution) of the anchorage shear stress is analysed. Based on the peak and residual test of the cohesive force and internal friction angle, the relationship between the anchoring force and buried depth and water content is established by analysing the factors influencing the anchoring force. It can be found from the field test that, according to the relationship established, the limit anchorage force of the anchor cable in the red clay stratum can be calculated and the water sensitivity of the anchor cable's limit anchorage force can be quantitatively analysed.
\end{abstract}

\section{Introduction}

Red clay is mainly distributed in the hot and subtropical climatic zones between latitudes $30^{\circ}$ north and $30^{\circ}$ south. Large areas of red clay are found in Asia, Europe, South America, and Africa [1-4]. Red clay is widely distributed in China, and it is mainly found in the southern provinces of China, with a total exposed area of more than 200,000 square kilometers. Due to the existence of the quaternary monsoon circulation, the red clay in the south of China underwent a complex laterisation process under the conditions of high temperature and humidity between the tropical and subtropical regions [5]. The location characteristics and engineering characteristics of red clay are obviously different in different regions due to the different environment and degree of weathering and laterisation $[3,4]$. As a common form of support for red clay slopes, the anchoring technique has been widely developed and applied since it was first used in soil layer anchoring in the 19th century. In the design of the anchorage support, the anchorage support force is determined by the magnitude and distribution of the anchorage shear stress. Without considering the influence of the bolt strength, the rock and soil body's anchoring force in the anchoring support is determined by the bond shear stress between bolt and anchoring agent, shear stress in the anchorage agent, and the shear stress of rock and soil mass itself. All three of the above may reach the limit value and cause damage. The damage location shall be determined by the one who reaches the limit value first. Many studies show that the interface between the anchoring agent and the rock 
and soil mass is the weakest of the three. Therefore, research has been conducted on the physical mechanics of the interface between the cohesive soil and structure through laboratory tests [6-9]. Li and Stillborg [6] presented a model of the shear stress distribution along a fully encapsulated rock bolt in tension, as shown in Figure 1. In their model, the elastic, softening, and debonding zones were considered, but with the limitation of linear behaviour within the softening zone. Ma et al. [7] presented an analytical model for fully encapsulated rock bolts subjected to tensile load in pull-out tests based on the bond-slip relationship describing the mechanical interaction at the bolt-grout interface, as shown in Figure 2. The model takes into account the residual shear stress in addition to the complete decoupling mechanisms. For calculation convenience, the anchorage shear stress is often assumed to be uniformly distributed, and the average bond strength is used to calculate the anchorage length. This anchoring force calculation method is used in the national specifications for slopes and foundation pits in China. In fact, the distribution of anchorage shear stress is not uniform. The classical distribution patterns are Phillips distribution [10,11] and unimodal distribution [12].

In fact, in the hard rock and soil layer, shear failure occurs at the interface because of the high strength of the rock and soil mass and the anchor solid. However, in soft soil, the interface strength of the anchor solid, affected by the anchorage, is greater than that of soft soil, and the shear failure does not occur at the interface position, but in the soft soil close to the anchor solid. Based on the correlation of the ratio of load transfer to soil shear strength as a function of pile movement, an analytical method for developing a theoretical load-settlement curve for axially loaded piles in clay is presented in the literature [13]. Wang [14] believed that the shear strength of the interface between the concrete and soil was equal and, based on this, Wang established the theoretical formula for calculating the pile lateral resistance with shear strength. Liu et al. [15] established a mathematical model of the soil shear strength index and pile lateral resistance based on Coulomb's law and, using this mathematical model, the relationship between the soil shear strength and pile lateral resistance and the changing characteristics of the pile lateral resistance with depth are analysed.

In the red clay stratum, the interface strength of the anchorage body and soil affected by grouting infiltration is greater than that of the soil, and the anchorage shear stress is directly determined by the shear strength of the soil. Under natural conditions, red clay has good engineering mechanical properties. According to the classical molar Coulomb theory, the shear strength of red clay is determined by the normal stress of the soil layer, the cohesion of the soil mass, and the angle of internal friction [16]. Under the condition of the low water content, red clay has good engineering mechanical properties. With the increase of water content, its engineering mechanical properties deteriorate sharply, which is mainly manifested in the deterioration of the soil cohesion and internal friction angle. Li et al. [17] studied the changing law of the peak and residual cohesive force and internal friction angle for undisturbed soil which

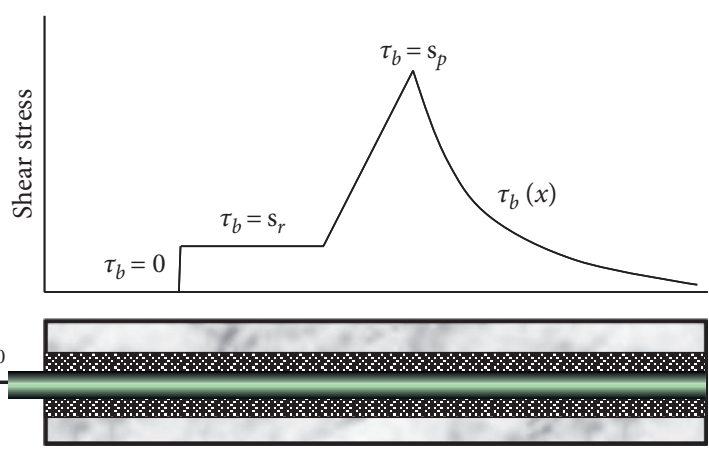

FIGURE 1: Distribution of shear stress along a fully grouted rock bolt subjected to an axial load in a coupled rock bolt [6].

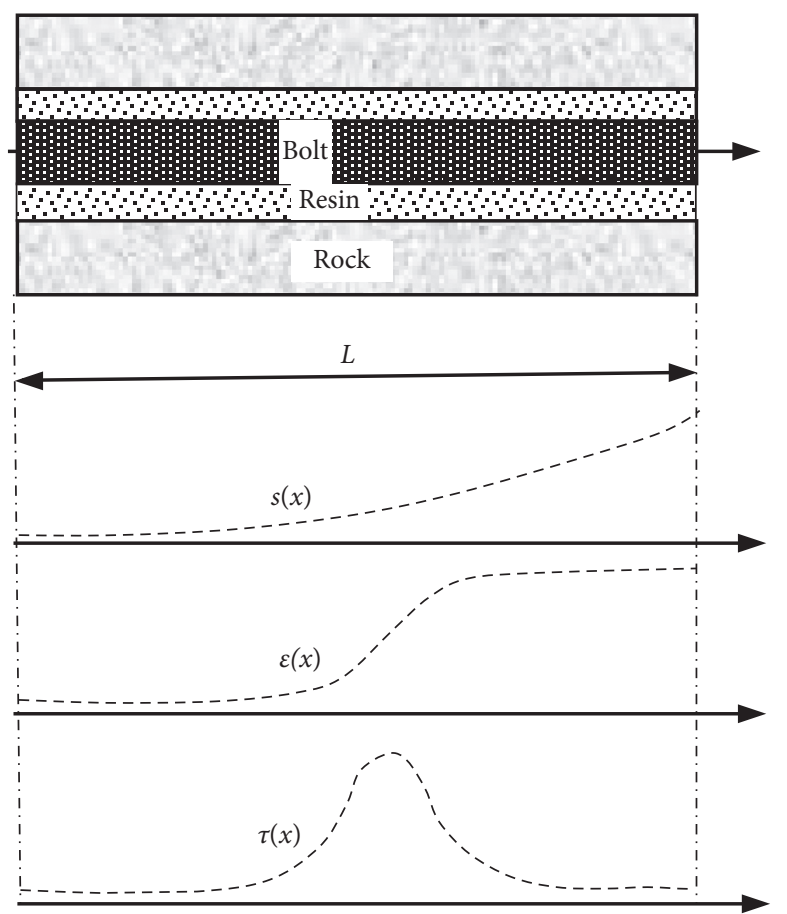

FIgURE 2: Analytical model of a fully grouted bolt subjected to a pull load at the bolt end [7].

was obtained through the indoor experiment. In the case of natural undisturbed water content, the peak and residual cohesive force decrease with the exponential relationship of water content, while the peak and residual internal friction angle decrease linearly with the water content range. Based on the traditional Culon-morper shear strength criterion, the changes of peak and residual shear strength with water content were obtained. Taking the red clay in the Yunfu section of Guangwu expressway as a sample, Liu and Zhang [18] studied water content influence on properties of red layers in Guangzhou metro line, China. The results should provide the reference for further research for water-induced damage mechanism or creep damage control of red layers in engineering practice. Taking the anchorage shear stress of the red clay formation as the research object, the change of water content as the influencing factor, and the shear strength as the approach, this paper mainly studies the 
distribution law of the anchorage force and water sensitivity of the red clay formation.

\section{Anchorage Stress Distribution Theory}

In the red clay stratum slope anchor cable support, the anchor cable is a straight tube type of the tension anchor cable, the bond strength between the anchor cable and the anchorage body is relatively stable, and the strength is greater, so they will not damage each other. Generally, the failure of the anchorage is a bond failure between the anchorage body and the rock-soil mass, or the failure of the rock-soil mass itself. The interface strength of the anchorage body and the soil mass affected by grouting infiltration is greater than that of the soil mass. The shear failure of the anchorage body and soil mass in red clay is marked by the shear failure of the soil mass.

\subsection{Classical Theory of Anchorage Shear Stress Distribution}

2.1.1. Phillips Distribution. When the anchorage length of the anchor cable is long enough and the rock-soil mass around the anchorage body does not experience shear failure, the shear stress of the rock-soil mass around the anchorage body can be considered as an exponential distribution along the length of the anchor cable, i.e., Phillips distribution [10, 11], as shown in Figure 3.

The Phillips distribution can be expressed as follows $[10,11]$ :

$$
\tau_{x}=\tau_{0} e^{-A x / d},
$$

where $x$ is the starting point of the anchorage section as the origin, pointing to the coordinate of the tail of the anchorage section $(\mathrm{m}) . \tau_{x}$ is the anchorage shear stress at point $x(\mathrm{kPa})$. $\tau_{0}$ is the anchorage shear stress of the anchorage segment starting point, taking the maximum anchorage segment in the red clay layer within the scope of the limit of the shear strength in geotechnical engineering $(\mathrm{kPa}) . d$ is the effective diameter of the anchorage body after grouting diffusion (m). A is a constant.

The anchor cable axial force $T_{x}$ can be obtained by integrating $l-x$ along the length of the anchorage section, as shown in equation (2), and the axial distribution of the anchor cable axial force along the anchor cable is also exponential, as shown in Figure 4.

$$
T_{x}=\frac{1}{A} \pi d^{2} \tau_{0}\left(1-e^{-A(l-x) / d}\right),
$$

where $T_{x}$ is the anchor cable axial force at the starting point $x$ from the anchorage section $(\mathrm{kN})$ and $l$ is the effective length of the anchorage section $(\mathrm{m})$.

The ultimate axial force of the anchor cable is

$$
T_{u}=\frac{1}{A} \pi d^{2} \tau_{0}\left(1-e^{-(A l / d)}\right) .
$$

The anchorage length $l$ is generally much larger than the diameter $d$ of the anchorage body.

When $l / d$ approaches infinity, the maximum value of equation (3) is

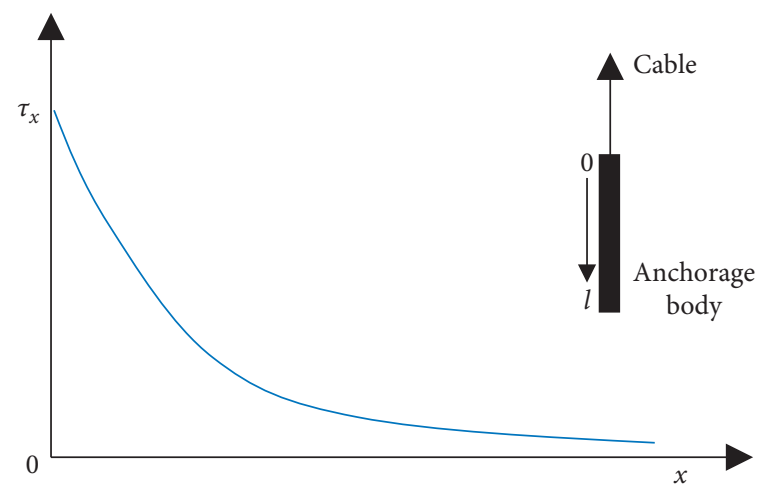

FIgURE 3: Exponential (Phillips) shear stress distribution [10, 11].

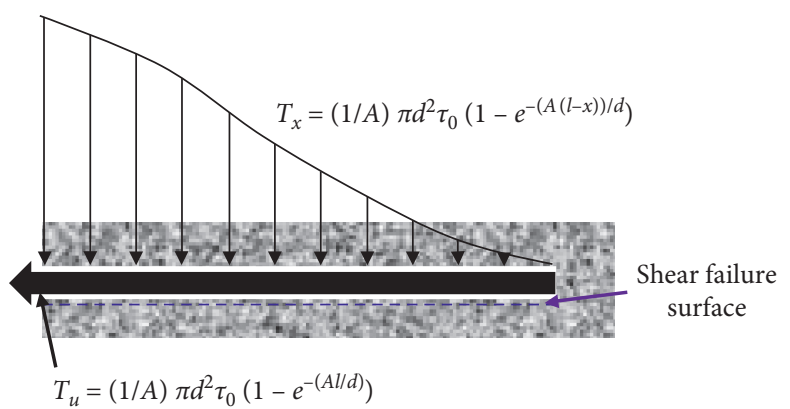

Figure 4: Axial force distribution for exponential distribution.

$$
T_{u}^{\max }=\frac{1}{A} \pi d^{2} \tau_{0},
$$

where $T_{u}^{\max }$ is the ultimate anchorage force of the anchor cable $(\mathrm{kN})$.

The abovementioned formula shows that, when the length of the anchorage section is larger than the diameter of the anchorage body, the increase of the anchorage length has little influence on the magnitude of the anchorage force, which is consistent with the test results of the rock-soil mass with low residual strength.

2.1.2. Uniform Distribution. The Phillips distribution theory is cumbersome in practical application. In order to simplify the calculation and facilitate engineering application, it is assumed that the shear stress of the anchorage body is uniformly distributed in the current slope specifications, as shown in Figure 5.

The expression $T_{x}$ of the anchor cable axial force at the starting point $x$ from the anchorage section is equation (5), and the axial distribution of the anchor cable axial force along the anchor cable is oblique, as shown in Figure 6:

$$
T_{x}=\alpha \pi d(l-x) \bar{\tau},
$$

where $a$ is the coefficient related to the shear strength of the rock-soil mass and $\bar{\tau}$ is the effective anchorage length within the limit of the shear strength in the geotechnical engineering average $(\mathrm{kPa})$.

The ultimate anchorage force of the anchor cable with uniform shear stress distribution is 


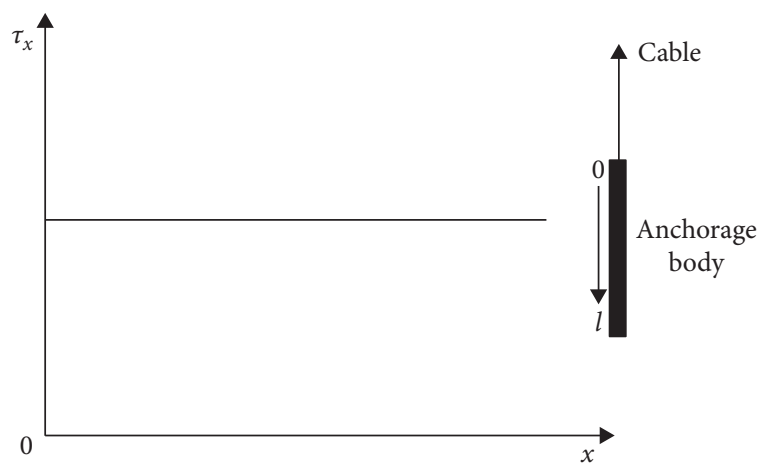

FIGURE 5: Shear stress for uniform distribution.

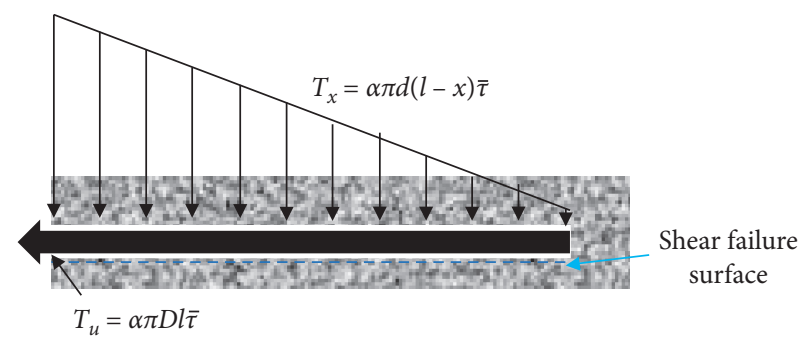

FIgURE 6: Uniform axial force distribution.

$$
T_{u}^{\max }=\alpha \pi d l \bar{\tau}
$$

2.2. The Distribution and Evolution of Shear Stress for Uniform-Exponential Pattern. In red clay, with increase of the anchoring force of the anchor cable, the rock-soil mass around the anchorage body at the initial point of the anchor cable and anchor segment first suffers shear failure, and then the failure gradually develops to the depth of the anchor segment. The shear stress value of the rock-soil mass when failure occurs is the peak shear strength. The rock-soil mass will not completely lose strength after destruction and the strength of the rock and soil after failure is called the residual strength. The development of rock-soil mass failure is a process in which the shear stress around the anchor body gradually decreases from the peak shear strength to the residual shear strength. Under constant conditions, the peak shear strength and residual shear strength of the rock-soil around the anchorage body in the anchor segment of the anchor cable are fixed values. According to the maximum tension, which is also called the anchorage force, of a tension type anchor cable, in the process of gradually increasing from large to small, the shear stress of the surrounding rock and soil mass along the length of the anchor cable can be divided into the following situations:

(1) When the length of the anchor cable is long and the axial force value of the anchor cable is small, the rock and soil around the anchorage body do not undergo shear failure. The rock and soil mass do not produce any sliding failure along the length of the anchor cable; that is, the maximum shear stress does not exceed the peak shear strength of the rock and soil mass. This stress distribution region is the nonslip region. The expressions of the shear stress distribution and ultimate anchorage force in the nonslip zone are equivalent to the expressions of exponential distribution. The shear stress distribution is expressed in equation (1), and the ultimate anchorage force is expressed in equation (2).

(2) With the increase of the anchor cable axial force, the initial point of the anchor segment will first reach the ultimate bearing capacity and then shear failure will occur. At this time, the ultimate shear stress is the peak shear strength of the rock and soil mass. As the anchorage force of the anchor cable continues to increase, the shear stress at the initial point of the anchorage section gradually decreases until the shear stress decreases to the residual shear strength value. The decrease of the shear stress from peak strength to residual strength is not a mutation process, but an asymptotic change in a region, which is a transition region. The shear stress distribution in the transition area is approximately exponential, and the shear stress distribution is symmetric with the nonslip region, as shown in Figure 7. In this case, the shear stress distribution can be expressed as equation (7) and the expression of limiting anchorage force is shown in equation (8).

$$
\begin{cases}\tau_{x}=\tau_{p} e^{-\left(A\left(x_{0}-x\right) / d\right)}, & 0 \leq x<x_{0}, \\ \tau_{x}=\tau_{p} e^{-\left(A\left(x-x_{0}\right) / d\right)}, & x_{0} \leq x,\end{cases}
$$

where $\tau_{p}$ is the peak shear strength of the rock-soil mass $(\mathrm{kPa})$ and $x_{0}$ is the position where the shear stress of the rock-soil mass reaches the peak strength.

The ultimate anchorage force of the anchor cable can be expressed as

$T_{u}=\frac{1}{A} \pi d^{2} \tau_{P}\left(1-e^{-\left(A\left(x_{0}\right) / d\right)}\right)+\frac{1}{A} \pi d^{2} \tau_{P}\left(1-e^{-\left(A\left(l-x_{0}\right) / d\right)}\right)$.

(3) When the anchor cable is long and strong enough and the axial force at the end of the anchor cable continues to increase, the rock-soil mass around the anchorage body exceeds the peak strength and passes through the transition zone within a certain length range at the beginning of the anchor section. The shear stress of the rock-soil mass is equal to the residual shear strength in this state. The area where the shear stress equals the residual shear strength is the relative slip zone. When the anchor cable anchorage section is long enough, the transition zone and the nonslip zone develop to the depth of the anchor section with the increase of the anchor cable axial force. In this case, there will be three areas in the anchorage section: the relative slip zone, the transition zone, and the nonslip zone. The shear failure has occurred in the rock and soil around the anchorage body in the relative slip 


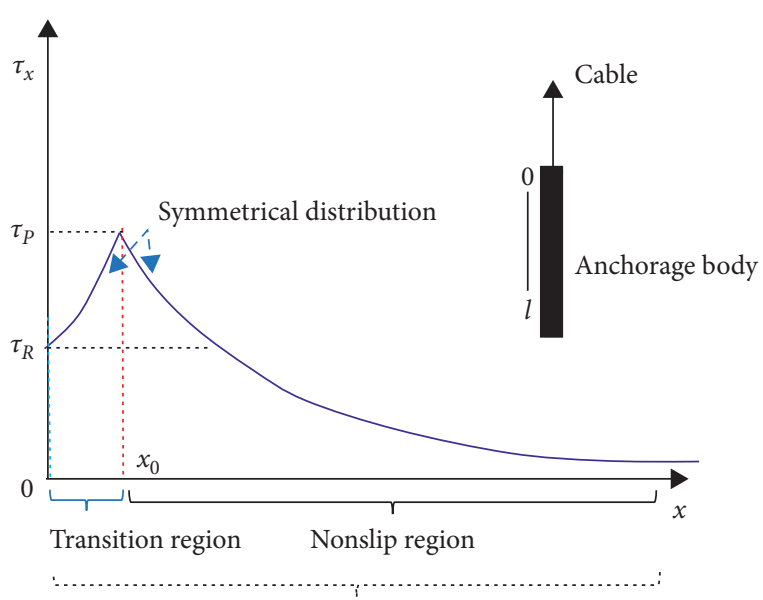

(Exponential distribution)

Figure 7: Double exponential shear stress distribution.

zone, where the shear stress is the residual shear strength. At this point, the shear stress distribution can be expressed as equation (9), and its distribution mode is shown in Figure 8. The expression of the ultimate anchorage force is shown in equation (10), and the ultimate anchorage force expression is shown in equation (11) when the anchorage length of the cable is relatively long:

$$
\begin{cases}\tau_{x}=\tau_{R}, & 0 \leq x<x_{1}, \\ \tau_{x}=\tau_{p} e^{-\left(A\left(x_{0}-x\right) / d\right),}, & x_{1} \leq x<x_{0}, \\ \tau_{x}=\tau_{p} e^{-\left(A\left(x-x_{0}\right) / d\right)}, & x_{0} \leq x,\end{cases}
$$

where $x_{1}$ is the starting position of the transition zone. The ultimate anchorage force of the anchor cable with a uniform-exponential shear stress distribution is

$$
\begin{aligned}
T_{u}= & \pi d x_{1} \tau_{R}+\frac{1}{A} \pi d^{2} \tau_{P}\left(1-e^{-\left(A\left(x_{0}-x_{1}\right) / d\right)}\right) \\
& +\frac{1}{A} \pi d^{2} \tau_{P}\left(1-e^{-\left(A\left(l-x_{0}\right) / d\right)}\right) .
\end{aligned}
$$

When $l / d$ tends to infinity, the ultimate anchorage force of the anchor cable is expressed as

$$
T_{u}=\pi d x_{1} \tau_{R}+\frac{1}{A} \pi d^{2} \tau_{P}\left(1-e^{-A\left(x_{0}-x_{1}\right) / d}\right)+\frac{1}{A} \pi d^{2} \tau_{P}
$$

(4) When the axial force at the end of the anchor cable increases to a state where slip failure of the whole anchorage section of the anchor cable occurs, the whole anchorage section of the anchor cable enters the slip zone in this state. The shear stress of the rocksoil mass around the anchorage section is all residual shear strength. The shear stress distribution can be expressed as equation (12), and its distribution mode

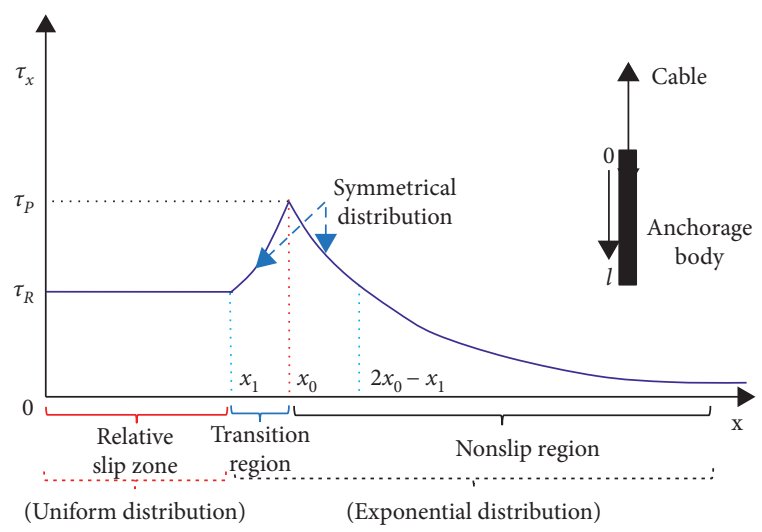

Figure 8: The shear stress distribution for the uniform index compound pattern.

is shown in Figure 9. The expression of the limiting anchorage force is shown in equation (13):

$$
\begin{aligned}
\tau_{x} & =\tau_{R}, \\
T_{u} & =\pi d l \tau_{R} .
\end{aligned}
$$

When the anchor cable length is appropriate, with the increase of the anchor axial force, namely, the anchoring force, the shear stress of the rock-soil mass surrounding the anchorage body will experience changes from single exponential distribution $(\mathrm{I}) \longrightarrow$ double single exponential distribution (II) $\longrightarrow$ uniform index (III) compound distribution $\longrightarrow$ uniform distribution type (IV) in a gradual change process. The evolution process of shear stress with uniform-exponential distribution is shown in Figure 10.

\subsection{Influence Factors of Uniform-Exponential Shear Stress} Distribution. The abovementioned analysis results in this paper are based on the fact that the peak shear strength and residual shear strength of the rock-soil mass around the anchorage body in the anchorage section are constant values, but they are in fact not constant values. The shear strength of the rock-soil mass is related to the stress state, cohesion, and internal friction angle of the rock-soil mass itself. The peak shear strength and residual shear strength can be expressed by equations (14) and (15), respectively:

$$
\begin{gathered}
\tau_{P}=c_{P}+\sigma \tan \varphi_{P}, \\
\tau_{R}=c_{R}+\sigma \tan \varphi_{R},
\end{gathered}
$$

where $\tau_{P}$ and $\tau_{R}$ are the peak shear strength and the residual shear strength of the rock-soil mass $(\mathrm{kPa})$, respectively, $c_{P}$ and $c_{R}$ are the peak cohesion and residual cohesion of the soil mass in the anchorage area $(\mathrm{kPa})$, respectively, $\varphi_{P}$ and $\varphi_{R}$ are the peak internal friction angle and residual internal friction angle of the rock-soil mass around the anchorage point $\left({ }^{\circ}\right)$, respectively, and $\sigma$ is the normal stress of the rocksoil mass around the anchor solid perpendicular to the anchor cable.

Normal stress, which is perpendicular to the anchor cable, is determined by the in-situ stress state, the depth, the 


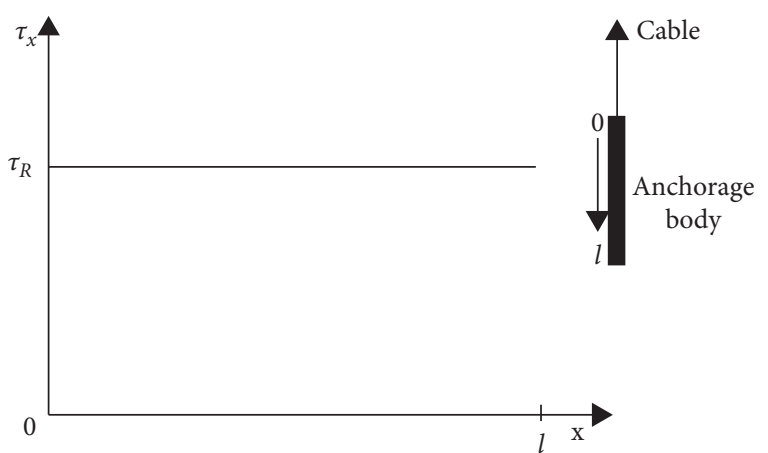

FIGURE 9: Uniform shear stress distribution (only includes the relative slip zone).

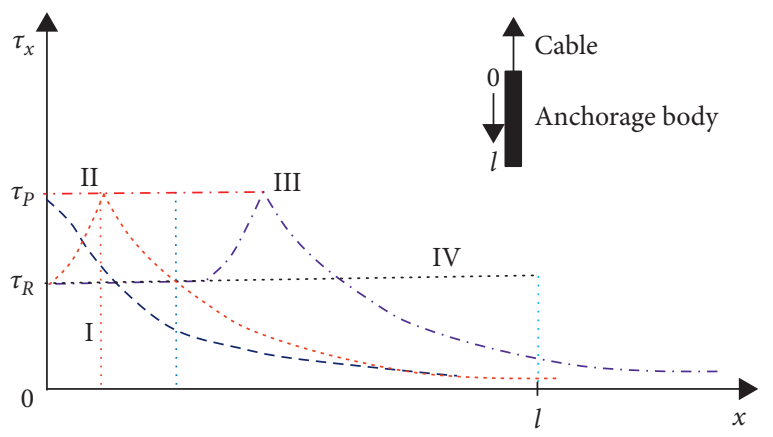

FIGURE 10: The evolution process of shear stress with uniformexponential distribution.

magnitude of external forces, and the restraint mode of the rock-soil mass surrounding the anchor. The larger the $\sigma$ value, the greater the peak and residual shear strength.

When the sigma is constant, the peak shear strength and residual shear strength of the rock-soil mass are determined by the peak cohesive force and internal friction angle and the residual cohesive force and internal friction angle, respectively. The peak cohesion and internal friction angle and the residual cohesion and internal friction angle of the rock-soil mass have a strong relationship with the properties of the rock-soil mass. Even in the same kind of rock-soil mass, the cohesive force and internal friction angle change with the water content of different anchorage sections. A lot of research has been carried out on the influence of the water content on the shear strength of red clay [16-18]. In order to study the effect of the water content on the peak and residual cohesion and internal friction angle of red clay, laboratory tests were conducted at three different sites in Bijie, Guizhou province, China (Figure 11). The basic information of the soil samples from the three sites is shown in Table 1 . According to different times of natural rainfall, the same sampling site was taken and a group of samples with different water contents were taken using the drilling sampling method. At sample point I, nine sets of samples were taken, at sample point II six sets of samples, and at sample point III nine sets of samples. According to the latest China national geotechnical test standard, the strain-controlled direct shear instrument was used in the test to measure the peak and residual value of the cohesion and the internal friction angle for the samples under different water contents. The experimental results of the peak cohesion and internal friction angle are shown in Figures 12 and 13. The residual experimental results are shown in Figures 14 and 15.

The laboratory test results for the red clay samples from sampling points I, II, and III show that the peak and residual values of cohesion and the internal friction angle for soil samples with the same water content at different positions are different. The results also show that the peak and residual values of the internal friction angle and the cohesion of red clay at the same sampling point decrease with increase of the water content. Specifically, with increase of the water content, the peak cohesion and residual cohesion of red clay have a negative exponential attenuation relationship with the water content. The peak internal friction angle and the residual internal friction angle of the red clay decreased linearly. The expressions of the cohesion force and internal friction angle at the same sampling point can be expressed in equations (16) and (17). These two expressions are applicable to both peak and residual parameters:

$$
\begin{aligned}
& c=a e^{-b w_{g}}+h, \\
& \varphi=f w_{g}+d,
\end{aligned}
$$

where $c$ is the cohesion force, $\varphi$ is the internal friction angle, $a$ and $h$ are the fitting parameters for the expressions of cohesion force, $f$ and $d$ are the fitting parameters for the expressions of internal friction angle, and $a, h, f$, and $d$ are constant values in the specific fitting formula.

The type of uniform index compound shear-stress distribution (shown in Figure 8 states III) contains the stress state at various stages of evolution, and the stress and the anchoring force expression also set I, II, and the expression of the IV state. The expression of stress and the anchoring force for states III is also a collective expression of I, II, and IV. Therefore, considering the influence of the stress state and moisture content, the stress and anchorage force distribution law of other states can be deduced from the uniform-exponential distribution expression. By substituting equations (14)-(17) into equation (9), the relationship between the anchorage shear stress and the influence of the stress state and water content can be obtained, as shown in the following equation:

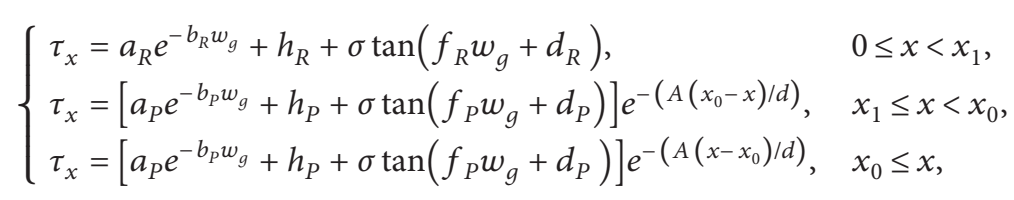



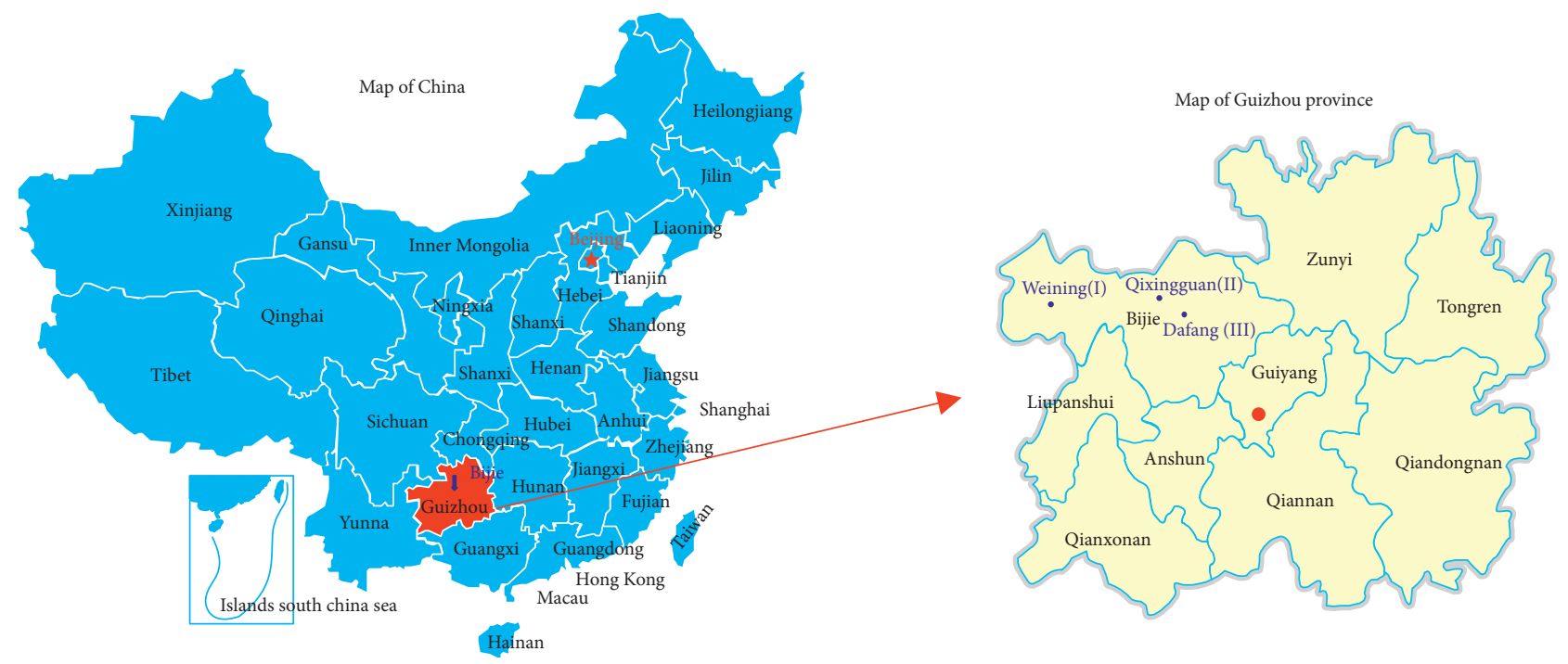

FIGURE 11: Location and distribution of sampling points.

TABLE 1: Basic information on sampling points.

\begin{tabular}{lccccc}
\hline Sampling point & Dry density $\left(\mathrm{g} / \mathrm{cm}^{3}\right)$ & Liquid limit $\left(w_{L}\right)$ & Plastic limit $\left(w_{p}\right)$ & Plasticity index $\left(I_{p}\right)$ & Test quantity $($ group $)$ \\
\hline I & 1.49 & 36.0 & 20.6 & 15.4 & 9 \\
II & 1.55 & 27.4 & 16.3 & 11.1 & 6 \\
III & 1.59 & 29.7 & 19.2 & 10.5 & 9 \\
\hline
\end{tabular}

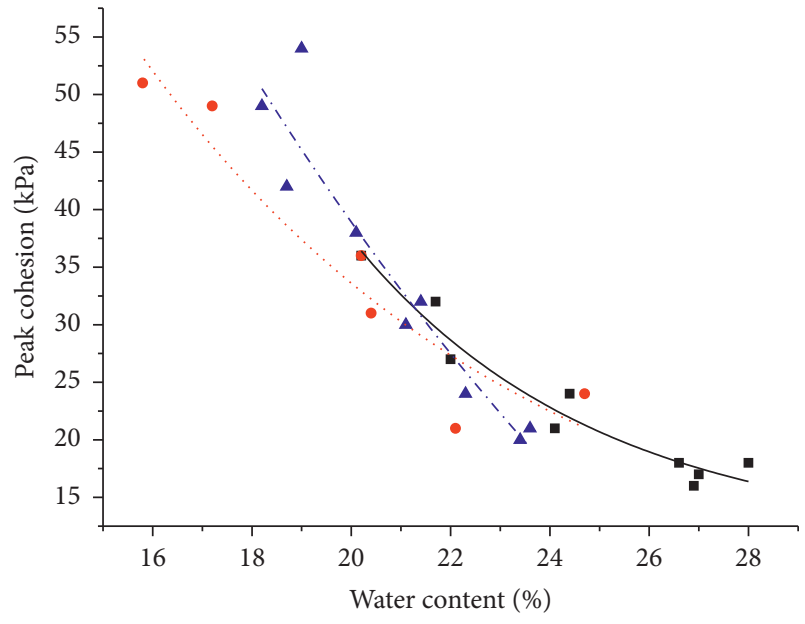

- I

- II

- III

_ I fitting curve

..... II fitting curve

-..- III fitting curve

FIgURE 12: The curve of peak cohesive strength with moisture content change.

where $w_{g}$ is the water content by weight $(\%), a_{R}, b_{R}$, and $h_{R}$ are the residual cohesion influence coefficients, $f_{R}$ and $d_{R}$ are the residual internal friction angle influence coefficients, $a_{P}, b_{P}$, and $h_{P}$ are the peak cohesion influence coefficients, and $f_{P}$ and $d_{P}$ are the peak internal friction angle influence coefficients.

The ultimate anchorage force of the anchor cable with uniform-exponential distribution is expressed as follows:
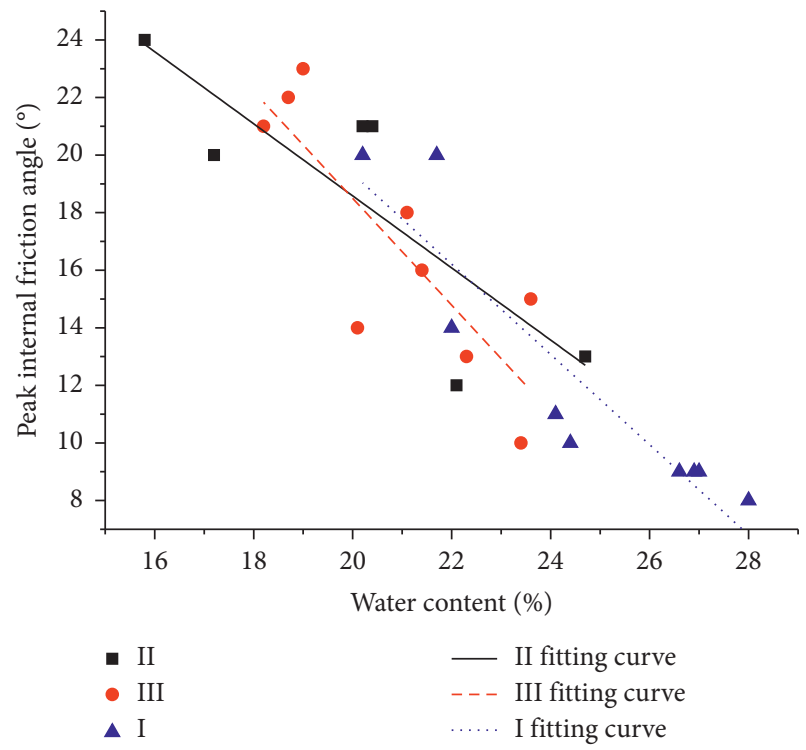

FIgURE 13: The curve of peak internal friction angle with moisture content change.

$$
\begin{aligned}
T_{u}= & \pi d x_{1}\left[a_{R} e^{-b_{R} w_{g}}+h_{R}+\sigma \tan \left(f_{R} w_{g}+d_{R}\right)\right] \\
& +\frac{1}{A} \pi d^{2}\left[a_{P} e^{-b_{P} w_{g}}+h_{P}+\sigma \tan \left(f_{P} w_{g}+d_{P}\right)\right] \\
& \cdot\left(1-e^{-A\left(x_{0}-x_{1}\right) / d}\right)+\frac{1}{A} \pi d^{2}\left[a_{P} e^{-b_{P} w_{g}}+h_{P}\right. \\
& \left.+\sigma \tan \left(f_{P} w_{g}+d_{P}\right)\right]\left(1-e^{-\left(A\left(l-x_{0}\right) / d\right)}\right) .
\end{aligned}
$$




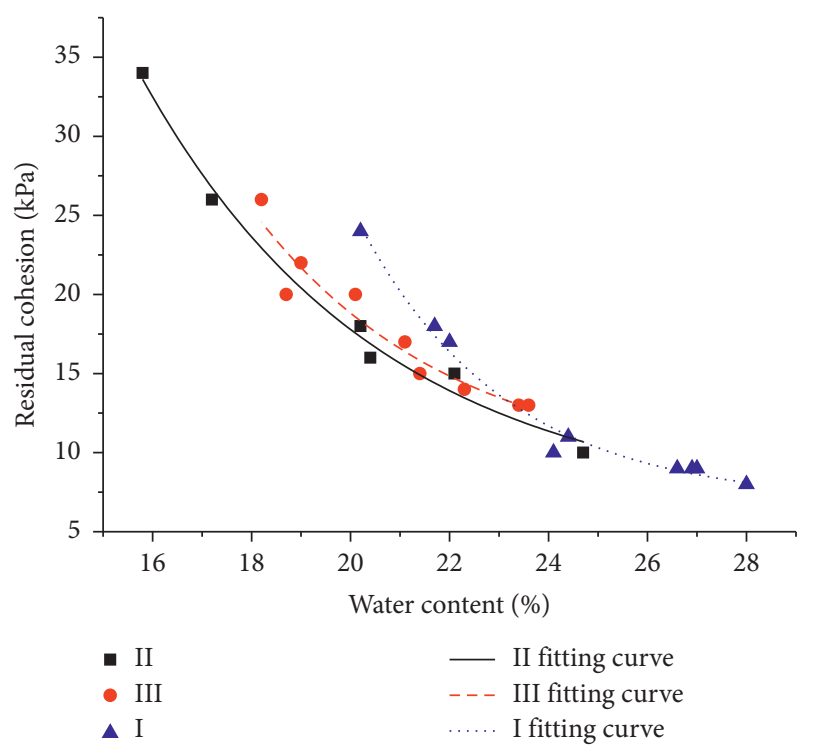

Figure 14: The curve of residual cohesive force with moisture content change.

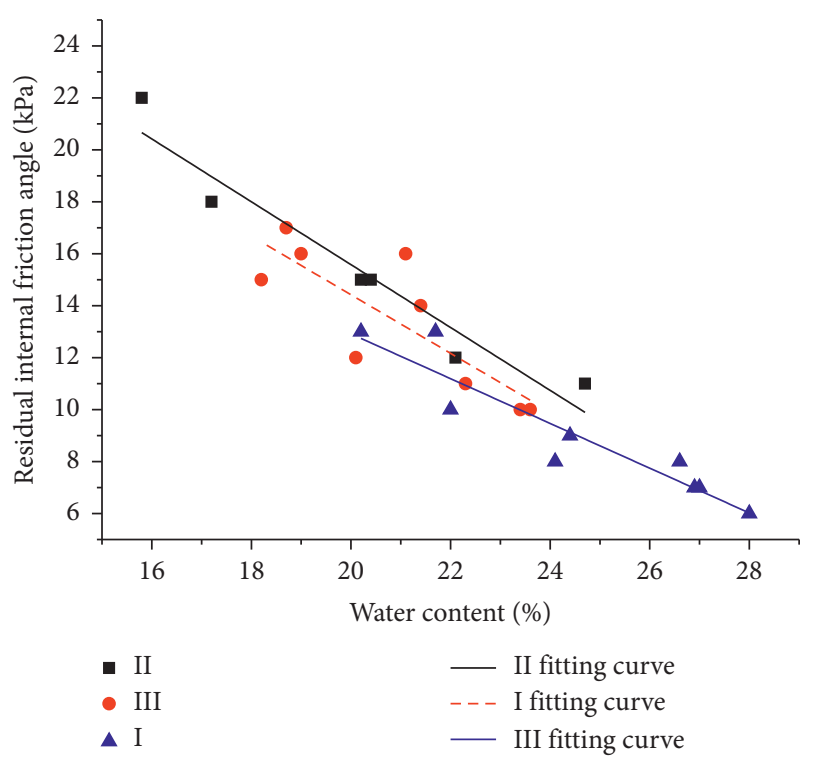

FIgURE 15: The curve of residual internal friction angle with moisture content change.

When $l / d$ approaches infinity, the ultimate anchorage force of the anchor cable is

$$
\begin{aligned}
T_{u}= & \pi d x_{1}\left[a_{R} e^{-b_{R} w_{g}}+h_{R}+\sigma \tan \left(f_{R} w_{g}+d_{R}\right)\right] \\
& +\frac{1}{A} \pi d^{2}\left[a_{P} e^{-b_{P} w_{g}}+h_{P}+\sigma \tan \left(f_{P} w_{g}+d_{P}\right)\right] \\
& \cdot\left(1-e^{-\left(A\left(x_{0}-x_{1}\right) / d\right)}\right)+\frac{1}{A} \pi d^{2}\left[a_{P} e^{-b_{P} w_{g}}+h_{P}\right. \\
& \left.+\sigma \tan \left(f_{P} w_{g}+d_{P}\right)\right] .
\end{aligned}
$$

Through the analysis of the distribution and evolution law of the uniform-exponential pattern, the expression of the shear stress and anchor cable anchorage force considering the effects of the stress state and water content can be converted from equations (18)-(20).

When $\tau_{R}=\tau_{x}$, the length of transition zone $l_{t}=x_{0}-x_{1}$ can be calculated by equation (18):

$$
l_{t}=x_{0}-x_{1}=-\frac{d}{A} \ln \left[\frac{a_{R} e^{-b_{R} w_{g}}+h_{R}+\sigma \tan \left(f_{R} w_{g}+d_{R}\right)}{a_{P} e^{-b_{P} w_{g}}+h_{P}+\sigma \tan \left(f_{P} w_{g}+d_{P}\right)}\right] .
$$

By analysing the shear stress distribution under the uniform-exponential pattern, when $x>2 x_{0}-x_{1}$ and $\tau_{x}<\tau_{R}$. When the anchor cable is in the maximum limit anchorage force, the length of the nonslip zone and of the transition zone are both $x_{0}-x_{1}$, and the length of the relative slip zone is $l-2 x_{0}+2 x_{1}$. Currently, the maximum limit anchorage force of the anchor cable is expressed as

$$
\begin{aligned}
T_{u \max }^{l}= & \pi d\left[l-2\left(x_{0}-x_{1}\right)\right] \tau_{R}+2 \frac{1}{A} \pi d^{2} \tau_{P}\left(1-e^{-\left(A\left(x_{0}-x_{1}\right) / d\right)}\right) \\
= & \pi d\left[l+2\left(\frac{d}{A} \ln \frac{\tau_{R}}{\tau_{P}}\right)\right] \tau_{R}+2 \frac{1}{A} \pi d^{2} \tau_{P}\left(1-\frac{\tau_{R}}{\tau_{P}}\right) \\
= & \pi d\left\{l+2 \frac{d}{A} \ln \left[\frac{a_{R} e^{-b_{R} w_{g}}+h_{R}+\sigma \tan \left(f_{R} w_{g}+d_{R}\right)}{a_{P} e^{-b_{P} w_{g}}+h_{P}+\sigma \tan \left(f_{P} w_{g}+d_{P}\right)}\right]\right\} \\
& \cdot\left[a_{R} e^{-b_{R} w_{g}}+h_{R}+\sigma \tan \left(f_{R} w_{g}+d_{R}\right)\right]+2 \frac{1}{A} \pi d^{2} \\
& \cdot\left[a_{P} e^{-b_{P} w_{g}}+h_{P}+\sigma \tan \left(f_{P} w_{g}+d_{P}\right)\right] \\
& \cdot\left\{1-\left[\frac{a_{R} e^{-b_{R} w_{g}}+h_{R}+\sigma \tan \left(f_{R} w_{g}+d_{R}\right)}{a_{P} e^{-b_{P} w_{g}}+h_{P}+\sigma \tan \left(f_{P} w_{g}+d_{P}\right)}\right]\right\} .
\end{aligned}
$$

Under the condition of a certain water content and buried depth, the maximum limit anchorage force of the anchor cable can be measured by field tests. At this point, the anchor cable anchoring length, effective diameter of the anchor solid after grouting diffusion, peak shear strength, and residual shear strength of the soil mass are fixed values. By substituting the abovementioned experimental data into equation (22), the constant $A$ can be solved, as shown below:

$$
A=\frac{2 \pi d^{2}}{T_{u \max }^{l}-\pi d l \tau_{R}}\left(\tau_{R} \ln \frac{\tau_{R}}{\tau_{P}}+\tau_{P}-\tau_{R}\right) .
$$

In this article, only the point I sample's experimental results are presented. The specific peak and residual fitting expressions of the cohesive force and internal friction angle data of the point I sample are equations (24)-(27). The test results fitting trend of the point II and III samples is the same as the fitting result for point I. The specific results are not given in detail in this article. 


$$
\begin{aligned}
& c_{\mathrm{IR}}=716.88 e^{-0.21 w_{g}}+6.37, \\
& \varphi_{\mathrm{IR}}=43.62-1.25 w_{g}, \\
& c_{\mathrm{IP}}=1568.80 e^{-0.2 w_{g}}+11.29, \\
& \varphi_{\mathrm{IP}}=50.71-1.57 w_{g},
\end{aligned}
$$

where $c_{I R}$ is the residual cohesion, $\varphi_{I R}$ is the angle of residual internal friction, $c_{\mathrm{IP}}$ is the peak cohesion, and $\varphi_{\mathrm{IP}}$ is the peak internal friction angle.
From the fitting results, the correlation coefficients (COD) of the residual and peak cohesion fitting relations and the test results are 0.9220 and 0.9495 . The correlation coefficients of the residual and peak internal friction angle fitting relations and the test results are 0.9362 and 0.9170 . The fitting correlation coefficients of all four are above $90 \%$. For the undisturbed soil of a specific project rather than the remolded soil in the laboratory, the degree of conformity is high and it can meet the accuracy requirements.

Equation (28) can be obtained by combining equations (16)-(18) and equations (24)-(27):

$$
\begin{cases}\tau_{I x}=716.88 e^{-0.21 w_{g}}+6.37+\sigma \tan \left(43.62-1.25 w_{g}\right), & 0 \leq x<x_{1}, \\ \tau_{I x}=\left[1568.80 e^{-0.2 w_{g}}+11.29+\sigma \tan \left(50.71-1.57 w_{g}\right)\right] e^{-\left(A\left(x_{0}-x\right) / d\right)}, & x_{1} \leq x<x_{0}, \\ \tau_{I x}=\left[1568.80 e^{-0.2 w_{g}}+11.29+\sigma \tan \left(50.71-1.57 w_{g}\right)\right] e^{-\left(A\left(x-x_{0}\right) / d\right)}, & x_{0} \leq x .\end{cases}
$$

Similarly, equation (22) becomes

$$
\begin{aligned}
T_{u \max }^{l}= & \pi d\left\{l+2 \frac{d}{A} \ln \left[\frac{716.88 e^{-0.21 w_{g}}+6.37+\sigma \tan \left(43.62-1.25 w_{g}\right)}{1568.80 e^{-0.2 w_{g}}+11.29+\sigma \tan \left(50.71-1.57 w_{g}\right)}\right]\right\}\left[716.88 e^{-0.21 w_{g}+6.37+\sigma \tan \left(43.62-1.25 w_{g}\right)}\right] \\
& +2 \frac{1}{A} \pi d^{2}\left[1568.80 e^{-0.2 w_{g}}+11.29+\sigma \tan \left(50.71-1.57 w_{g}\right)\right]\left\{1-\left[\frac{716.88 e^{-0.21 w_{g}}+6.37+\sigma \tan \left(43.62-1.25 w_{g}\right)}{\left.\left.1568.80 e^{-0.2 w_{g}+11.29+\sigma \tan \left(50.71-1.57 w_{g}\right)}\right]\right\}} .\right.\right.
\end{aligned}
$$

\section{Engineering Application}

The field test is located behind the 5th and 6th buildings of the urban harbour project in Bijie City, Guizhou province (Figure 11). The plane layout of the test site is shown in Figure 16(a). This field test position is also the red clay water sensitivity test location of sample I and the variation rule of the mechanical parameters of red clay with water content is shown in equations (24)-(27). The test site is a manually treated slope. The lower half of the excavation slope is $1: 0.75$ with the anchor cable lattice beam support, and the upper part is a natural slope with bolt and shotcrete support. In order to ensure consistent buried depth of the anchor cable, the direction of the anchor cable is parallel to the natural slope line and the depth distance is controlled at $10 \mathrm{~m}$. The slope profile and anchor cable support mode are shown in Figure16(b).

Three groups of red clay samples were taken from the middle point of the anchorage section of the anchor cable at test points 1-3 during the tensioning of the anchor cable for laboratory tests. The sampling depth, water content, density, peak cohesion and internal friction angle, and the residual cohesion and internal friction angle of the sample are shown in Table2. In this experiment, a low-pressure grouting method is adopted to fill cement slurry, so the effective diameter $d$ of the anchor solid after grouting diffusion is approximately equal to the diameter of anchor cable drilling. Three anchor cables were installed at test points 1-3, as shown in Figure 16(a). The relationship between the limit and residual anchorage tension and displacement is shown in Figure 17. The experimental data of the drilling diameter, anchorage length, and limit and residual tensile force of test points 1-3 are shown in Table 3 .

The last rows of Tables 2 and 3 are the average values of the red clay samples and anchor rope test parameters. The last column in Table 2 is the value of the constant $A$ calculated according to equation (23). Through the analysis of the test and calculation results, it can be found that the average value of $\mathrm{A}$ of the three experimental points and the average value of $A$ calculated according to the average value of the experimental parameters according to equation (22) is approximately 0.0119 . The soil sample used in the test is come from sampling I point. By substituting the $A$ value and relevant data in Tables 2 and 3 into equation (29), the relationship between the ultimate anchorage force of the anchor cable in the red clay layer at the research location and the change of water content can be obtained, and the relationship is shown in Figure 18. According to equation (29) and the constant $A$ value reverse calculated by the field test, the ultimate anchorage force of the anchor cable under the condition of arbitrary water content and buried depth can be estimated and can be used to optimise the engineering design. 


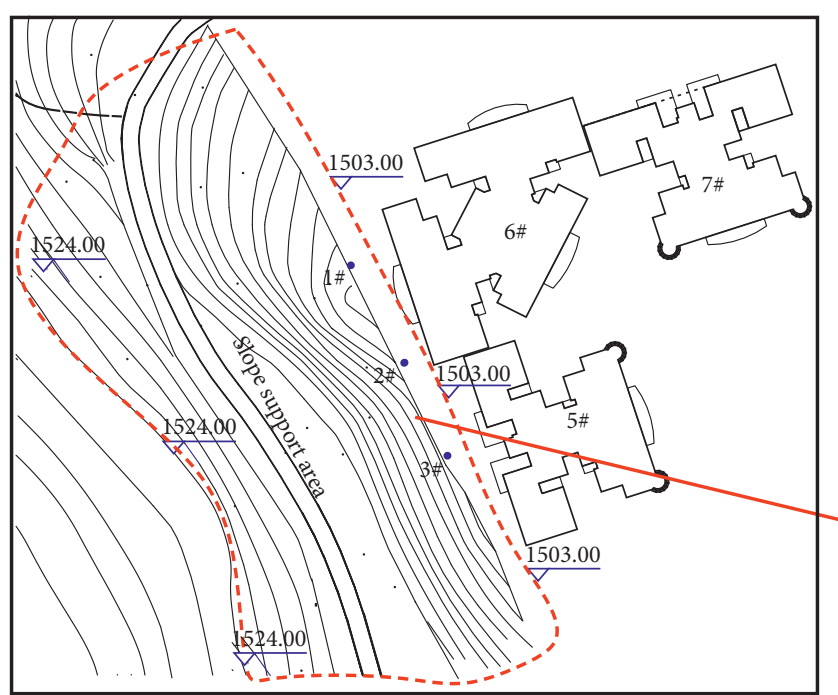

(a)

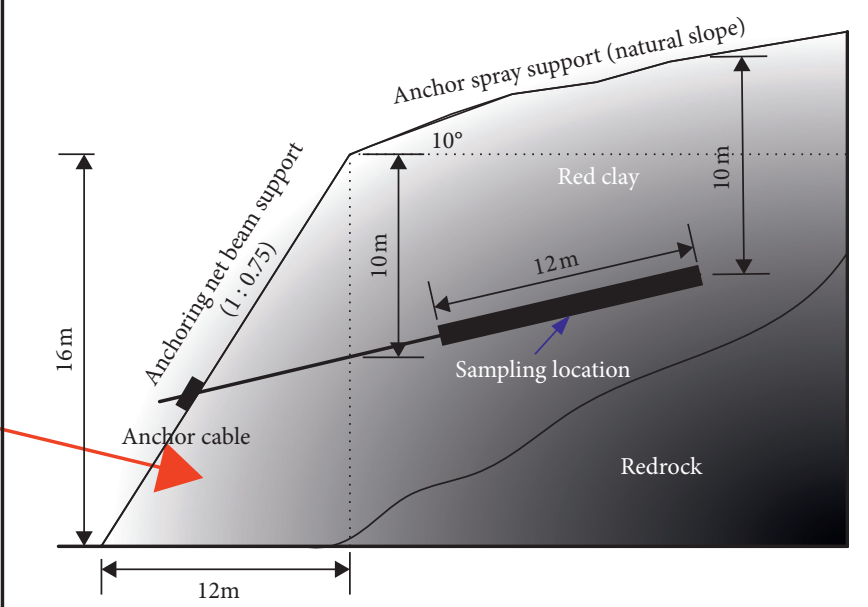

(b)

FIGURE 16: (a) Slope and anchor cable location map of the test site. (b) Test site slope profile.

TABle 2: Basic parameters and experimental data of the anchor cable.

\begin{tabular}{lcccccrrr}
\hline $\begin{array}{l}\text { Serial } \\
\text { number }\end{array}$ & $\begin{array}{c}\text { Sampling depth } \\
(\mathrm{m})\end{array}$ & $\begin{array}{c}\text { Peak strength } \\
\text { Cohesion } \\
(\mathrm{kPa})\end{array}$ & $\begin{array}{c}\text { Internal friction } \\
\text { angle }\left(^{\circ}\right)\end{array}$ & $\begin{array}{c}\text { Residual strength } \\
\text { Cohesion } \\
(\mathrm{kPa})\end{array}$ & $\begin{array}{c}\text { Internal friction } \\
\text { angle }\left({ }^{\circ}\right)\end{array}$ & $\begin{array}{c}\text { Density } \\
\left.\mathrm{cm}^{3}\right)\end{array}$ & $\begin{array}{c}\text { Water content } \\
(\%)\end{array}$ \\
\hline $1 \#$ & 10 & 36 & 18 & 17 & 12 & 1.93 & 21.3 \\
$2 \#$ & & 38 & 19 & 18 & 14 & 0.0120 \\
$3 \#$ & & 35 & 20 & 16 & 13 & 1.94 & 20.9 & 0.0119 \\
Mean value & & 36.33 & 19 & 17 & 13 & 1.93 & 21.6 & 0.0119 \\
\hline
\end{tabular}

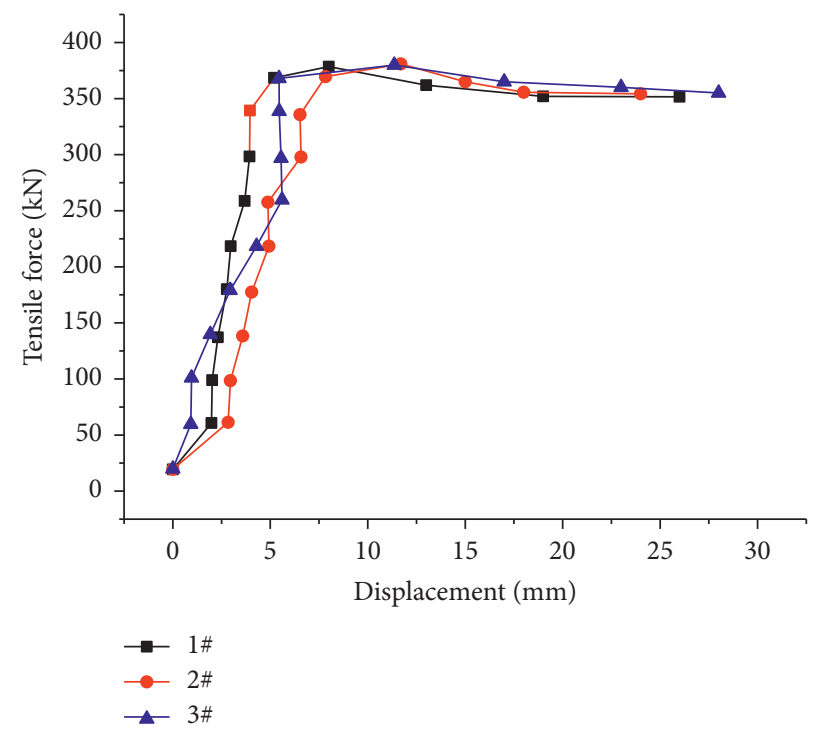

Figure 17: Relation diagram of anchor cable tension and displacement.

TABLE 3: Basic parameters and experimental data of soil samples.

\begin{tabular}{lcccr}
\hline Serial number & $d(\mathrm{~m})$ & $l_{t}(\mathrm{~m})$ & Ultimate tension $(\mathrm{kN})$ & Residual tension $(\mathrm{kN})$ \\
\hline $1 \#$ & 0.13 & 12 & 368 & 289 \\
$2 \#$ & & & 418 & 321 \\
$3 \#$ & & 378 & 263 \\
Mean value & & 388 & 291 \\
\hline
\end{tabular}




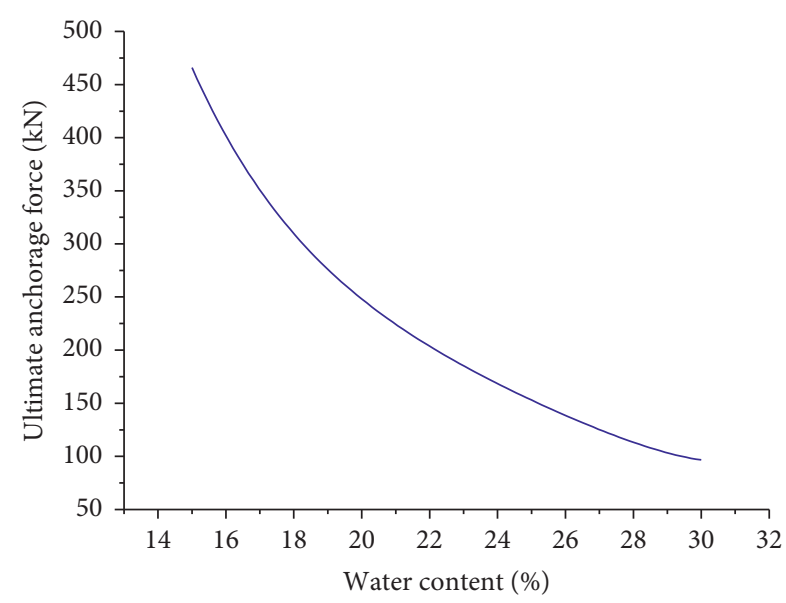

FIGURE 18: Relationship diagram of limiting anchorage force with water content.

\section{Conclusion}

Based on the classical Phillip exponent and uniform anchorage shear stress distribution theory, the distribution law of the anchorage shear stress in red clay can be considered as a uniform-exponential distribution by using the characteristics of the peak shear strength and residual shear strength of the rock-soil mass. As the anchorage force increases gradually, the shear stress of the rock-soil mass around the anchor solid may experience a gradual change process from single exponential distribution (state I) $\longrightarrow$ double single exponential distribution (state II) $\longrightarrow$ uniform index complex distribution (state III) $\longrightarrow$ uniform distribution type (state IV). The stress of state III includes the other four stages in the process of the evolution of the stress state, and the stress and the anchoring force expression of state III also synthesize the expressions for the states I, II, and IV.

The peak and residual value of cohesion and the internal friction angle for the soil samples of the same water content at different positions are different. The peak and residual values of the internal friction angle and cohesion of red clay at the same sampling point decrease with the increase of water content. With increase of the water content, the peak cohesion and residual cohesion of red clay have a negative exponential attenuation relationship with the water content. The peak internal friction angle and the residual internal friction angle of the red clay decreased linearly.

Based on the testing of the peak and residual cohesion and internal friction angle of red clay and the field tensioning test, the ultimate anchorage force of the anchor cable in red clay formation under a certain water content can be estimated and the water sensitivity of the ultimate anchorage force can be judged.

\section{Data Availability}

All data generated or analysed during this study are included in this work.

\section{Conflicts of Interest}

The authors declare that they have no conflicts of interest.

\section{Acknowledgments}

This work was supported by the National Natural Science Foundation of China (Grant no. 51574248), Guizhou Department of Education Youth Talent Growth Project of China (Grant nos. [2019]161 and [2019]162), Guizhou Department of Science and Technology Joint fund of China (Grant no. LH [2014] 7522), Guizhou University of Engineering Science Dr Fund (Grant no. 2018016), and Guizhou Science and Technology Plan Project of China (Grant no. [2018]5622).

\section{References}

[1] R. M. Madu, "An investigation into the geotechnical and engineering properties of some laterites of Eastern Nigeria," Engineering Geology, vol. 11, no. 2, pp. 101-125, 1977.

[2] S. A. Ola, "Mineralogical properties of some Nigerian residual Soil in relation with building problems," Engineering Geology, vol. 15 , no. 2, pp. 1-13, 1980.

[3] U. Mahalinga-Iyer and D. J. Williams, "Engineering properties of a lateritic soil profile," Engineering Geology, vol. 31, no. 1, pp. 45-58, 1991.

[4] E. L. Krinitzsky, D. M. Patrick, and F. C. Townsend, Geology and Geotechnical Properties of Laterite Gravel, Department of the Army, Corps of Engineers, Waterways Experiment Station, Soils and Pavements Laboratory, Washington, DC, USA, 1976.

[5] H. Zhang and J. Liu, "Microstructures, mineral compositions, and mechanical properties of red-layers in southern China," Advances in Materials Science and Engineering, vol. 2018, Article ID 9601386, 9 pages, 2018.

[6] C. Li and B. Stillborg, "Analytical models for rock bolts," International Journal of Rock Mechanics and Mining Sciences, vol. 36, no. 8, pp. 1013-1029, 1999.

[7] S. Ma, J. Nemcik, and N. Aziz, "An analytical model of fully grouted rock bolts subjected to tensile load," Construction and Building Materials, vol. 49, pp. 519-526, 2013.

[8] I. W. Farmer, "Stress distribution along a resin grouted rock anchor," International Journal of Rock Mechanics and Mining Sciences \& Geomechanics Abstracts, vol. 12, no. 11, pp. 347351, 1975.

[9] J. G. Potyondy, "Skin friction between various soils and construction materials," Géotechnique, vol. 11, no. 4, pp. 339-353, 1961.

[10] S. H. E. Phillips, Factors Affecting the Design of Anchorages in Rock, Cementation research Ltd., London, UK, 1970.

[11] B. Stillborg, "Experimental investigation of steel cables for rock reinforcement in hard rock," Lulea University of Technology, Luleå, Sweden, Dissertation, 1984.

[12] X. Sun, "Grouted rock bolt used in underground engineering in soft surrounding rock or in highly stressed regions," International Journal of Rock Mechanics and Mining Sciences \& Geomechanics Abstracts, vol. 22, pp. 93-99, 1985.

[13] H. M. Coyle and L. C. Reese, "Load transfer for axially loaded piles in clay," Journal of the Soil Mechanics and Foundations Division, vol. 92, no. 2, pp. 1-26, 1966.

[14] J. Wang, "Study on pile lateral resistance calculation by shear strength index," Geotechnical Engineering Technique, vol. 3, pp. 180-182, 2000. 
[15] K. Liu and Y. Liu, "Relationship between pile lateral friction and shear strength and its variation with depth," Site Investigation Science and Technology, vol. 1, pp. 5-8, 2018.

[16] K. Terzaghi, R. Peck, and G. Mesri, Soil Mechanics, John Wiley \& Sons, New York, NY, USA, 1996.

[17] L. Li, C. Chen, X. Zhang, D. Deng, and L. Han, "Study on the water sensitivity analysis of red clay shear strength based on culon-morper rule," IOP Conference Series: Earth and Environmental Science, vol. 371, no. 4, p. 4, 2019.

[18] J. F. Liu and H. Z. Zhang, "Water content influence on properties of red-layers in Guangzhou metro line, China," Advances in Materials Science and Engineering, vol. 2017, Article ID 4808909, 12 pages, 2017. 